\title{
A interação como indicador de qualidade na avaliação da educação a distância: um estudo de caso com docentes, tutores e discentes
}

\author{
Enedina Betânia Leite de Lucena Pires Nunes ${ }^{1}$ \\ Isabel Cristina Auler Pereira ${ }^{2}$ \\ Tânia Suely Azevedo Brasileiro ${ }^{3}$
}

Resumo: As tecnologias da informação e comunicação (TIC) adentraram no contexto educacional e estão demandando novas ações das instituições de ensino, especialmente no que se refere a modalidade de oferta de cursos na formação de professores. Valoriza-se cada vez mais a interação e a troca de informação entre professor e aluno com a mediação das TIC. Nesse contexto, a educação a distância $(\mathrm{EaD})$ situa-se como uma importante modalidade. Esta pesquisa tem como objetivo avaliar como se configura a interação entre docentes, tutores e estudantes de um curso de licenciatura em EaD, conforme os indicadores de avaliação integrantes dos Referencias de Qualidade e do Instrumento de Avaliação de Cursos, do Ministério da Educação. A abordagem qualitativa foi adotada a partir de um estudo de caso com 107 participantes do $6^{\circ}$ módulo do curso de Biologia EaD, sendo 11 docentes, 17 tutores e 79 estudantes, utilizando-se da análise documental. Constata-se que a interação repercute diretamente nas práticas do curso estudado como indicador de qualidade de avaliação apresentando características reativas. Por outro lado, o Instrumento de Avaliação não apresenta indicadores com critérios de análise que explicitem quando a interação promovida como garantia de padrão de qualidade na formação de professores atenda às propostas do curso.

Palavras-chave: Interação. Educação a distância. Formação de professores.

\section{Interaction as quality indicator in assessment of distance education: a case study with teachers, students and tutors}

Abstract: Information and communication technologies (TIC) have entered the educational context and are demanding new actions from educational institutions, especially regarding modalities for the provision of courses in teacher training. The interaction and exchange of information between teacher and student with the mediation of TIC is increasingly valued. In this context, distance education (EaD) is an important modality. This research aims to evaluate the configuration of the interaction among professors, tutors and students in the course of distance as the evaluation indicators of the Quality of References and Courses Assessment Instrument, the Ministry of Education. The qualitative approach was adopted from a case study with 107 participants of the 6th module of the course of Biology EaD, being 11 teachers, 17 tutors and 79 students, using documentary analysis. It appears that the interaction affects directly in the practices of the studied course as an indicator of quality presenting reactive characteristics. On the other hand, the Assessment Instrument does not present indicators with criteria of analysis that explain when the interaction promoted as a guarantee of quality standard in teacher training meets the course proposals.

Key words: Interaction. Distance education. Teacher training. 


\section{Introdução}

Os novos cenários globalizados, a política de expansão da educação superior brasileira implementada pelo Ministério da Educação (MEC) e a evolução tecnológica demandam novas ações das universidades, especialmente no que se refere a novas modalidades de oferta de cursos de graduação. Nesse contexto, a educação a distância (EaD) ou mediada pelas tecnologias da informação e comunicação, situa-se como uma importante modalidade.

De acordo com as Diretrizes Curriculares Nacionais (DCNs) (BRASIL, 2015a), a formação de professores é "[...] indispensável para o projeto nacional da educação brasileira, em seus níveis e suas modalidades da educação [...]" (BRASIL, 2015a, p. 8). As DCNs consideram dentre os princípios que norteiam a formação inicial e continuada, "a avaliação e regulação dos cursos de formação" (BRASIL, 2015a, p. 8), e que se leve em conta a realidade dos ambientes das instituições educativas, para que conduzam o(a) egresso(a) ao "uso competente das Tecnologias de Informação e Comunicação (TIC) para o aprimoramento da prática pedagógica e a ampliação da formação cultural dos(das) professores(as) e estudantes" (BRASIL, 2015a, p. 9).

Há, portanto, uma relação importante entre a avaliação dos cursos de formação de professores e o uso das TIC no processo educativo, as quais devem estar explicitadas no projeto pedagógico do curso (PPC), de maneira competente e acessível, para o aperfeiçoamento do processo ensino-aprendizagem e a ampliação da formação da cultura docente e discente.

O interesse por esta temática decorre da experiência profissional da pesquisadora na área de avaliação institucional e de cursos de graduação, tanto presencial como a distância da Universidade Federal do Tocantins (UFT), tornando-se relevante a contribuição para o processo de supervisão e regulação da educação superior, assim como para a melhoria da qualidade dos cursos nessa modalidade sintonizada com as demandas de formação no estado do Tocantins.

A abordagem qualitativa foi adotada nesta pesquisa a partir de um estudo de caso no curso de Biologia EaD da Universidade Federal do Tocantins (UFT). De acordo com Creswell (2007), nos estudos de caso, o pesquisador explora um evento ou uma atividade, relacionado por tempo e atividade e coleta dados durante um período de tempo prolongado. O estudo de caso como pesquisa qualitativa "contribui, de forma inigualável, para a compreensão que temos dos fenômenos individuais, organizacionais, sociais e políticos” (YIN, 2001, p. 21). 
A interação como indicador de qualidade na avaliação da educação a distância: um estudo de caso com docentes, tutores e discentes

Esta pesquisa descritiva apresenta os fatos e fenômenos contemplados pela realidade do referido curso. Uma de suas características é a utilização de técnicas padronizadas de coletas de dados, tais como o questionário (TRIVIÑOS, 1987), que foi aplicado aos docentes, tutores e estudantes, composto de oito questões fechadas e uma aberta. As questões fechadas tiveram opções de respostas baseadas numa escala de cinco conceitos, representados por Muito Alto; Alto; Médio; Baixo e Muito Baixo, que foram adaptados da escala original do Instrumento de Avaliação do MEC que contém os conceitos: Não Atende; Insuficiente; Suficiente; Muito Bom/Muito Bem e Excelente. Conforme dispõe a Lei do Sinaes $\mathrm{n}^{\mathrm{o}}$ 10.861/2004, no $\S 2^{\circ}$ do Art. $4^{\circ}$ "A avaliação dos cursos de graduação resultará na atribuição de conceitos ordenados em uma escala com 5 (cinco) níveis, a cada uma das dimensões e ao conjunto das dimensões avaliadas" (BRASIL, 2004, p. 3).

A última questão, aberta, foi trabalhada por meio de análise de conteúdo de forma qualitativa e contextualiza com base nas concepções sobre o processo de interação entre docentes, tutores e estudantes no curso de Biologia EaD da UFT. Adotou-se a nomenclatura para docente (Dn), para tutor (Tn) e para aluno (An), sendo "n" o número de sequência dos respondentes ( 1 é o primeiro que respondeu, 2 é o segundo que respondeu, 3 é o terceiro e assim por diante), sendo referenciados ao longo do texto pela indicação de A1 a A20 para os alunos, D1 a D7 para os docentes e T1 a T9 para os tutores.

A análise de conteúdo foi a técnica utilizada neste estudo, compreendendo segundo Bardin (1977), três fases: 1) pré-análise, 2) exploração do material e 3) tratamento dos resultados e interpretação dos dados. A primeira fase, a pré-análise, compreendeu a pesquisa e coleta dos documentos e a seleção de fontes sobre a educação a distância no contexto nacional e local, tais como: legislação brasileira e regional, documentos da instituição pesquisada, o projeto pedagógico do curso, os documentos oficiais e o referencial teórico sobre a interação. A segunda fase teve por objetivo identificar os termos ou abordagens que remetessem à temática de interação. A terceira e última etapa consistiu no tratamento dos resultados e interpretação dos dados. A partir disso, foi feita a discussão dos resultados da pesquisa apresentando a análise dos dados obtidos com a aplicação dos questionários aos sujeitos da pesquisa.

Os participantes da pesquisa foram os docentes e tutores das disciplinas do $6^{\circ}$ módulo e os estudantes matriculados nas respectivas disciplinas deste módulo, no primeiro semestre de 2015, do curso de Biologia EaD, da Universidade Federal do Tocantins. Esse módulo corresponde à segunda metade do curso, incluindo a disciplina de estágio curricular supervisionado. Os módulos mais avançados $\left(7^{\circ}\right.$ e $\left.8^{\circ}\right)$ não estavam sendo ofertados pelo curso 
no ano de 2015, por isso não foram incluídos no estudo. A intenção não foi investigar os préconcluintes e concluintes, até porque não havia a oferta de módulos mais avançados, mas somente os que haviam iniciado o estágio curricular supervisionado, visto que a prática realizada no estágio propicia uma vivência maior na docência como campo de atuação e reflexão sobre o mercado de trabalho.

O estudo compreendeu o período de 2005 ao primeiro semestre do ano de 2015. Abordou o período de implantação da educação a distância na Universidade Federal do Tocantins (UFT), em 2005, com a criação do curso de Biologia EaD, em caráter experimental, a partir da elaboração de projeto apresentado pelo Consórcio Setentrional aprovado pelo MEC em 2004. Aos poucos, a UFT foi implantando novos cursos nessa modalidade, as licenciatura em Química (2010), Física (2010) e Matemática (2015) e o bacharelado em Administração Pública (2014) e formando os professores conteudistas, tutores e professores das disciplinas, mas entende-se que há necessidade de um aprofundamento em relação aos mecanismos de interação entre os sujeitos da aprendizagem (docentes, tutores e estudantes) tendo como fundamento os elementos constantes nos Referenciais de Qualidade para Educação Superior a Distância (BRASIL, 2007) para esta modalidade e aos resultados dos processos de avaliação de cursos mediados pelas tecnologias da informação e comunicação.

\section{A interatividade e interação na educação a distância: reflexões iniciais}

A virtualidade está cada vez mais presente no cenário educacional. A revolução tecnológica abre caminhos para uma reestruturação da teoria e da prática educacional, do desenvolvimento da autonomia e possibilidades de aquisição de novas aprendizagens por parte dos docentes e dos discentes. Santaella (2001 apud NOVA; ALVES, 2006, p. 118) se refere à revolução tecnológica da seguinte maneira:

\footnotetext{
Propiciada, entre outros fatores, pelas mídias digitais, a revolução tecnológica que estamos atravessando é psíquica, cultural e socialmente muito mais profunda do que foi a invenção do alfabeto, do que foi a explosão da cultura de massas, com os seus meios técnico-mecânicos eletrônicos de produção e transmissão de mensagens. Muitos especialistas em cibercultura não têm cessado de alertar para o fato de que a revolução de teleinformática, também chamada de revolução digital, é tão vasta a ponto de atingir proporções antropológicas importantes, chegando a compará-la com a revolução neolítica. Para se ter uma ideia das consequências trazidas por essa revolução basta dizer que a nova ordem econômica, social e cultural mundializada não seria possível sem ela. Na base dessa revolução está o processo digital.
}

$\mathrm{Na}$ realidade, a utilização da internet no âmbito educacional passou a ser uma exigência da cibercultura, entendida por Lévy (1999, p. 17) como o "conjunto de técnicas (materiais e intelectuais), de práticas, de atitudes, de modos de pensamento e de valores que se desenvolvem juntamente com o crescimento do ciberespaço", este definido como "o espaço 
A interação como indicador de qualidade na avaliação da educação a distância: um estudo de caso com docentes, tutores e discentes

de comunicação aberto pela interconexão mundial dos computadores e das memórias dos computadores" (LÉVY, 1999, p. 92).

Atuar nesse ambiente significa "estar junto virtual", dialogar, trocar informações, ideias e experiências, construir e produzir conhecimento. "As interações por meio dos recursos disponíveis no ambiente propiciam as trocas individuais e a constituição de grupos colaborativos que interagem, discutem problemáticas e temas de interesses comuns, pesquisam e criam produtos ao mesmo tempo em que se desenvolvem" (ALMEIDA, 2003, p. $334)$.

Em seu artigo "Criar e professorar um curso online: relato de experiência", Marco Silva (2006), sustenta que é fundamental não subutilizar a interatividade e relata a sua experiência como professor quando precisou desenvolver um curso em ambiente online que superasse com a transmissão de conteúdos prontos e promovesse interatividade, aprendizagem, sociabilização online e inclusão digital. Para o autor é preciso investir na criação de cursos interativos, baseados em ambientes virtuais de aprendizagem (salas de aula online) em que os estudantes possam participar e colaborar na construção da comunicação e do conhecimento.

Nas práticas na educação a distância torna-se relevante a capacidade da interação e a interatividade entre os sujeitos, assim como os meios e os conteúdos do conhecimento. Tal capacidade leva ao desenvolvimento de competências e habilidades, a tomada de decisão, a criatividade e a emancipação do educando, aspectos fundamentais para a sua formação profissional, inserção no mercado do trabalho e como cidadão (BRASIL, 2014, 2016).

Ao se destacar posicionamentos teóricos sobre a interação, aponta-se uma diferenciação entre o que é interativo e o que é reativo. Williams (1979 apud SANTAELLA, 2004) considerava as tecnologias interativas como sendo reativas e foram rebatizadas adiante por Primo $(2000,2003)$ de interação mútua e interação reativa. A proposta teórica de Williams (1979) é que os sistemas interativos deveriam abranger autonomia, criatividade e atingir um novo estágio em que o emissor e receptor envolvidos na relação interativa sejam agentes ativos enquanto se comunicam e dialogam, não estejam restritos a poucas possibilidades reativas planejadas antecipadamente.

Koehler e Carvalho (2012, p. 379) afirmam que "Na educação a distância, a mediação pedagógica precisa ser baseada na docência mediadora, a partir de interações mútuas entre professor e estudante com pressupostos pautados no diálogo". Esta afirmação é com base no conceito de interação mútua de Primo (2003), no sentido de contribuir com a aprendizagem e a construção do conhecimento na modalidade de educação a distância. Portanto, vale salientar 
que os projetos pedagógicos de cursos ofertados nessa modalidade devem contemplar atividades didáticas que priorizem a interação mútua mediada pelo professor e tutor, utilizando-se de ferramentas incorporadas ao ambiente virtual de aprendizagem (AVA), além de corpo de docentes, de tutores e equipe técnica qualificados.

A interação mútua se caracteriza por ser um sistema aberto de relações interdependentes, recíprocas, no contexto social e temporal, em que "A própria relação entre os interagentes é um problema que motiva uma constante negociação" (PRIMO, 2011, p. 228). Ou seja, "não faz sentido observar uma ação como expressão individual ou como mensagem transmitida", mas "no contexto global do sistema" (PRIMO, 2003, p. 100). Neste tipo de interação, “onde se engajam dois ou mais agentes, o relacionamento evolui a partir de processos de negociação" (PRIMO, 2000, p. 88), sem a previsão de resultados. Opera-se por meio de ações interdependentes entre cada agente ativo e criativo, que influencia o comportamento do outro e também o seu próprio comportamento. O fluxo na interação mútua é dinâmico e em desenvolvimento, sendo que a interação vai sendo construída e permanentemente definida pelos interagentes. Segundo Primo (2000, p. 90) "Para que uma interface seja plenamente interativa, ela necessita trabalhar na virtualidade, possibilitando a ocorrência da problemática e viabilizando atualizações".

Por outro lado, a interação reativa se caracteriza por ser um sistema fechado de relações lineares, unilaterais, limitadas e determinísticas, de estímulo e resposta pelas pessoas envolvidas na interação. Um exemplo é quando se clica em um link, que direciona sempre para uma página determinada, sem pode alterar, com a interconexão pré-estabelecida e manipulada pelo emissor, prejudicando a comunicação e a capacidade de argumentação. $\mathrm{O}$ processo reativo se baseia em uma relação de estímulo que acarretará a mesma resposta quando se repetir a interação. Já quanto à operação e os sistemas reativos são marcados pela ação e reação, ou seja, um polo age e o outro reage. Quanto à relação, a interação reativa pressupõe a sucessão de dois processos que subentendem uma causa e um efeito, como por exemplo, um possível clique do usuário para acontecer (PRIMO, 2000, 2003).

Esses dois tipos de interação destacados foram retomados quando se analisou os dados coletados da pesquisa, no sentido de avaliar como se configura a interação a partir dos sujeitos da pesquisa (docentes, tutores e estudantes), no curso de Biologia, modalidade EaD, da UFT. 
A interação como indicador de qualidade na avaliação da educação a distância: um estudo de caso com docentes, tutores e discentes

\section{A interação como indicador de qualidade na avaliação da educação superior a distância}

O acompanhamento e a qualidade da mediação entre estudantes, professores e tutores constituem-se indicadores imprescindíveis para o desempenho e a avaliação de cursos e programas na educação a distância. Segundo os Referenciais de Qualidade para Educação Superior a Distância (BRASIL, 2007, p. 10), “O princípio da interação e da interatividade [...] por se constituir em indicador fundamental para a indução da qualidade na educação a distância, deve ser garantido no uso de qualquer meio tecnológico a ser disponibilizado". Por sua vez, o processo de avaliação prevê no Instrumento de Avaliação de Avaliação de cursos de graduação presencial e a distância (BRASIL, 2015b), os mecanismos de interação entre docentes, tutores e estudantes, como um indicador de avaliação que pode garantir a qualidade de curso mediado pelas tecnologias de informação e comunicação de forma contínua e permanente.

\subsection{Referenciais de qualidade para a educação superior a distância preconizados pelo Ministério da Educação}

Como referencial para análise dos mecanismos de interação foi utilizado o documento Referenciais de Qualidade para Educação Superior a Distância (BRASIL, 2007). Trata-se de um referencial do Ministério da Educação relativo a processos de regulação, supervisão e avaliação da educação a distância contendo orientações sobre a concepção teóricometodológica e a organização de sistemas de educação a distância. $\mathrm{O}$ documento tem como fundamento os resultados dos procedimentos avaliativos realizados pelo MEC em diversos programas nesta modalidade no país, no sentido de atender aos requisitos mínimos de qualidade. Dias Sobrinho (2005) sinaliza a avaliação como uma dimensão imprescindível da Universidade. Para ele,

\footnotetext{
A instituição precisa saber, de forma permanente e integrada, quais são os valores dominantes nas suas atividades de ensino, pesquisa e extensão e nas suas práticas administrativas. [...] é um exercício com forte sentido pedagógico que não só permite rediscutir os projetos e prioridades essenciais da universidade, suas relações com a ciência, a tecnologia, as letras e as artes e suas interações com a sociedade, como também contribuir para a elaboração mais consistente dos diversos sentidos da instituição (DIAS SOBRINHO, 2005, p. 33).
}

Complementando, o autor afirma que a avaliação "deve ser uma atividade sistemática e permanente que resulte em uma compreensão global e integrada da Universidade, [...] de todos os aspectos e setores científicos, pedagógicos, políticos e administrativos" (DIAS SOBRINHO, 2005, p. 33-34). 
Nessa abordagem sistêmica, os Referenciais de Qualidade para Educação Superior a Distância (BRASIL, 2007) compreendem dimensões que envolvem aspectos pedagógicos, recursos humanos e infraestrutura das instituições de ensino superior e são relevantes para a avaliação dos cursos a distância. Descrevem 8 (oito) elementos estruturantes de um curso superior a distância que devem ser apresentados no projeto pedagógico de curso nessa modalidade. São eles: concepção de educação e currículo no processo de ensino e aprendizagem; sistemas de comunicação; material didático; avaliação; equipe multidisciplinar; infraestrutura de apoio; gestão acadêmico-administrativa e sustentabilidade financeira.

Destacam que o indicador "Sistemas de Comunicação" refere-se às comunicações síncronas e assíncronas como promotoras da interação entre docentes, tutores e estudantes, as quais possibilitam mais autonomia ao aluno e colocam o professor como mediador da aprendizagem. Nessa mediação, as diversas mídias a serem utilizadas nas atividades educativas devem estar em consonância com o projeto pedagógico do curso e compatíveis com o contexto socioeconômico dos atores envolvidos, além de desenvolver habilidades e competências específicas. Abordam, ainda, a importância do uso da tecnologia educacional na aprendizagem como forma de proporcionar efetiva interação e o desenvolvimento de atividades e projetos compartilhados, referindo-se ao princípio da interação e a interatividade como fundamental no processo de comunicação, independentemente do recurso tecnológico disponibilizado.

Essa interação entre professores, tutores e estudantes tem como escopo evitar o isolamento do estudante, fator apontado como uma das principais causas da perda de qualidade e de evasão nos cursos a distância, além de motivar a aprendizagem colaborativa, o respeito e a solidariedade com o outro, possibilitando ao estudante a participação coletiva. Nessa perspectiva, um curso superior a distância precisa estar apoiado em um sistema de comunicação que permita o retorno rápido de questões referentes ao conteúdo, à orientação de aprendizagem, de maneira a promover a interação entre os docentes, tutores e estudantes e com os responsáveis pela gestão acadêmica e administrativa (BRASIL, 2007).

Primo (2000) aponta diferenciações em contextos interativos que permitem perceber que a qualidade da interação varia em relação às características dos sistemas envolvidos (aberto e fechado). Complementando essa compreensão de interação, Watlzlawick, Beavin e Jackson (1967, p. 108) afirmam que “A interação pode ser considerada como um sistema. Portanto, os sistemas interacionais serão dois ou mais comunicantes no processo de (ou no nível de) definição da natureza de suas relações”. 
A interação como indicador de qualidade na avaliação da educação a distância: um estudo de caso com docentes, tutores e discentes

Em linhas gerais, os Referenciais de Qualidade para Educação Superior a Distância (BRASIL, 2007) aqui abordados orientam a gestão e organização dos cursos e programas ofertados a distância, apresentando indicadores de qualidade, que envolvem aspectos pedagógicos, recursos humanos e infraestrutura. Contudo, há necessidade de maior reflexão sobre "Sistemas de comunicação" para avaliação dos cursos de graduação a distância.

\subsection{Instrumento de avaliação de cursos de graduação presencial e a distância}

Os processos avaliativos referidos no Decreto $\mathrm{n}^{\circ}$ 5.622/2005 (BRASIL, 2005) dizem respeito aos atos de credenciamento e renovação de credenciamento de instituições e dos cursos ou programas a distância a serem realizados mediante avaliação in loco, aplicando-se o Instrumento de Avaliação de Cursos de Graduação presencial e distância (BRASIL, 2015b). Vale ressaltar que tal documento é considerado quando da realização do processo de avaliação do MEC, no âmbito do curso. O formulário contempla 69 indicadores e três dimensões: organização didático-pedagógica; corpo docente e tutorial e infraestrutura. Além destes, ocurso deverá também atender aos requisitos legais que são essencialmente regulatórios, por isso não fazem parte do cálculo do conceito da avaliação.

Com vistas ao atendimento ao objetivo desta pesquisa, foram aprofundadas as reflexões sobre o indicador "1.19 - Mecanismos de interação entre docentes, tutores e estudantes" do Instrumento de Avaliação de cursos de graduação presencial e a distância (BRASIL, 2015b), da primeira dimensão, que são definidos de acordo com o Glossário como “o conjunto de estruturas de tecnologia de informação e comunicação, os respectivos procedimentos e as formas de utilização que caracterizam a dinâmica da comunicação e da interação entre os sujeitos envolvidos nos processos acadêmicos e de ensino e aprendizagem (BRASIL, 2015b, p. 44).

Analisando o Instrumento de Avaliação dos cursos de graduação presencial e a distância (BRASIL, 2015b), no que se refere às exigências de interação entre os sujeitos da aprendizagem - docentes, tutores e estudantes - verifica-se que não há uma explicitação da estrutura disponibilizada capaz de favorecer a aprendizagem, considerando aspectos da interação nestes ambientes. O critério de análise no Instrumento para o indicador "1.19 Mecanismos de interação entre docentes, tutores e estudantes" apresenta 5 (cinco) níveis de conceitos: (1 - não existente; 2 - insuficiente; 3 - suficiente; 4 - muito bem; e 5 - excelente)", que caracterizam critérios de caráter subjetivo quanto ao que se entende por termos como "de maneira insuficiente", "de maneira suficiente", "atendem muito bem" e "de maneira 
excelente". Ou seja, o processo de avaliação não busca medir se há excelência na interação produzida como garantia de padrão de qualidade do curso em estudo, mas sim, se existem níveis de qualidade na avaliação do curso.

Observa-se que termos como "interação", "informação e comunicação", "mídias", "tecnologia de informação e comunicação (TIC)", "ambientes virtuais de aprendizagem (AVA)", "tempo e espaço", estão ausentes nos critérios de avaliação do Instrumento de Avaliação dos cursos de graduação presencial e a distância (BRASIL. 2015b), a não ser na definição do Glossário (BRASIL, 2015b, p. 44), que não faz parte do cálculo do conceito da avaliação. Além do mais, os indicadores considerados em uma avaliação "não são entidades isoladas, se interpenetram e se desdobram em outros subtópicos" (BRASIL, 2007, p. 8).

Embora o MEC aponte nos "Referenciais de Qualidade para Educação Superior a Distância (BRASIL, 2007) que os princípios da interação e da interatividade são fundamentais e devem ser valorizados e garantidos, o processo de avaliação não prevê no Instrumento de Avaliação dos cursos de graduação presencial e a distância (BRASIL, 2015b) a obrigatoriedade da qualidade quanto aos mecanismos de interação entre docentes, tutores e estudantes. Esse é um indicador de avaliação que pode garantir a qualidade de um curso mediado pelas tecnologias de informação e comunicação de forma contínua e permanente.

\section{Análise dos dados e resultados do estudo empírico}

Para a realização da pesquisa foram aplicados questionários por meio do Google Drive, a 107 participantes do $6^{\circ}$ módulo do curso de Biologia $\mathrm{EaD}$, sendo 11 docentes, 17 tutores e 79 estudantes. As respostas foram obtidas de 20 (vinte) estudantes (20\%), 7 (sete) docentes (47\%) e 9 (nove) tutores (53\%), no período de dezembro de 2015 a fevereiro de 2016. As questões foram formuladas a partir das categorias de análise: faixa etária; tempo de atuação em EaD; nível de interatividade entre os participantes; feedback/resposta aos alunos com relação as dúvidas do conteúdo; nível de interação síncrona; nível de interação assíncrona; indicação das tecnologias que promovem maior interação; nível de utilidade dos diferentes itens (moodle, dinâmica do grupo, fórum de discussão, material didático, relevância dos encontros presenciais, tutoria, videoaulas, mural, podcast, portfólio, perguntas frequentes) para o andamento das atividades e aspectos que poderiam melhorar a interação no curso.

Quanto à faixa etária, os alunos estão em sua maioria entre 18 e 30 anos; os docentes

estão acima de 45 anos, e os tutores entre 31 e 35 anos. É importante observar que os alunos se constituem de um público relativamente jovem, o que se pressupõe uma geração mais 
A interação como indicador de qualidade na avaliação da educação a distância: um estudo de caso com docentes, tutores e discentes

conectada com as tecnologias digitais. Sobre a atuação em EaD, os docentes em sua maioria estão entre 1 e 5 anos e os tutores entre 6 e 10 anos.

Em relação à interação, foi perguntado aos alunos do Curso de Biologia EaD: "Como você avalia o nível de interatividade (Muito Baixo, Baixo, Médio, Alto e Muito Alto) entre (Aluno x Docente, Aluno x Tutor e Aluno x Aluno)"? A mesma pergunta foi feita para os docentes e tutores. A maioria dos alunos avaliou que entre (Aluno x Docente e Aluno x Tutor) é igualmente médio, já para (Aluno x Aluno), o nível de interatividade é Alto. Os docentes em sua maioria consideraram os níveis propostos: Baixo para (Docente x Aluno); Médio em igual quantidade para (Docente x Tutor, Docente x Docente e Aluno x Aluno). Na percepção da maioria dos tutores, o nível de interatividade entre (Tutor x Aluno e Tutor x Docente) é igualmente Médio; e Baixo igualmente para (Tutor x Tutor como Aluno x Aluno).

Quando perguntados sobre o feedback/resposta, os alunos, em sua maioria considera o nível médio. Tutores e estudantes relataram que é preciso "Agilidade na correção dos trabalhos (A2); melhor acesso ao moodle, com perguntas respondidas pelo professor ou tutores [...] (A3); Resposta das dúvidas dos estudantes em tempo hábil” (T9). Como a comunicação entre professores, tutores e alunos não ocorre diariamente na $\mathrm{EaD}$, a motivação dos alunos é um desafio que pode ser intensificado por meio do feedback/resposta rápido e permanente na realização das atividades, contribuindo para incentivar à discussão, além de promover autonomia para que percebam os avanços, erros, limitações e problemas.

Buscando saber mais sobre a participação nos chats, videoconferências, fóruns, $e$ mails, foi questionado aos alunos, docentes e tutores sobre o nível de interação síncrona e assíncrona no curso. Os dados mostraram que o nível de interação síncrona é igualmente baixo a médio na percepção da maioria dos alunos, e baixo para os docentes e tutores. Em relação ao nível de interação das ferramentas assíncronas foi medianamente avaliado pelos alunos, docentes e tutores com destaque para o correio eletrônico (e-mail). Os e-mails trocados pressupõem que há interação mútua, ou seja, há um engajamento por parte de docentes, tutores e alunos. Como diz Primo (2011, p. 71), “interação é um processo no qual o sujeito se engaja”.

Aos alunos, docentes e tutores foi perguntado quais tecnologias eles consideram que promovem maior interação. Os dados coletados mostraram que a maioria considera o e-mail, mesmo assim, segundo o aluno A7, "o que precisa melhorar é apenas a comunicação entre professores e alunos, pois alguns não respondem e-mails". Já para o aluno A12, “a comunicação por e-mail é muito demorada para respostas dos tutores”. Ou seja, o professor precisa planejar a mediação da aprendizagem, no sentido de valorizar a interação e a 
comunicação entre os alunos. Estes dados estão consoantes com os termos presentes no Relatório da Diretoria de Tecnologias Educacionais (DTE), órgão responsável pela articulação, promoção e gerenciamento dos cursos a distância na UFT, que afirma ser o e-mail uma ferramenta ainda muito utilizada para a comunicação no curso que possibilita a troca de mensagens e o envio de arquivos anexados, permitindo a discussão assíncrona entre eles (UNIVERSIDADE FEDERAL DO TOCANTINS, 2015).

$\mathrm{Na}$ sequência do e-mail em se tratando da utilização no curso, encontra-se o fórum, que de acordo com Primo (2001), serve de interface tanto para interações mútuas quanto reativas, dependendo de seu uso e objetivo. Desta forma, esta interface permite que os alunos, docentes e tutores troquem experiências e informações por meio de mensagem circulada e comentada no ambiente virtual de aprendizagem (AVA), por exemplo, a plataforma moodle utilizada no curso, o que pode promover uma interação mútua. Por outro lado, é uma ferramenta que registra as opiniões de forma linear, limitada e estática entre os participantes, que pouco motiva o intercâmbio de ideias promovendo uma interação reativa. Com relação ao uso desta ferramenta, o aluno A16 aponta "Os alunos também poderiam responder ou perguntar nos fóruns [...]. Hoje tem apenas a opção de ler os posts, mas não é possível comentá-los, como já ocorreu em outros semestres".

$\mathrm{Na}$ educação a distância, as interações mútuas são necessárias e fundamentais para se estabelecer um processo interativo ao ensino online baseado em apostilas digitalizadas, ou seja, na interação reativa. Com relação a isto, três alunos e um tutor comentaram sobre a necessidade de apostilas digitais e materiais didáticos atualizados, mais direcionados a licenciatura e com uma linguagem mais dinâmica e visual.

Na sequência, a utilização do chat aparece em nível de utilização após o e-mail e fórum. É uma das ferramentas de maior potencial para a interação mútua, na opinião de Primo (2001), pois a troca de mensagens textuais acontece de forma rápida com ou sem imagens anexadas, além do mais, permite que os alunos, docentes e tutores dialoguem e se aproximem sem qualquer proximidade física ou geográfica.

$\mathrm{Na}$ sequência do e-mail, fórum e chat, encontra-se a videoconferência. Conforme afirma Primo (2001) é uma ferramenta de interação mútua que integra as vantagens dos chats acrescentando recursos como a emissão e visualização de imagens em vídeo por meio do uso de webcams, onde os interagentes podem ver como se comportam fisicamente os participantes no diálogo e vice-versa. Contudo, devido ao grande número de dados da imagem do vídeo, a transmissão pode ser prejudicada limitando sobremaneira o envio de informações em tempo real. Neste sentido, o docente D5 considera como um aspecto a melhorar a interação seria o 
A interação como indicador de qualidade na avaliação da educação a distância: um estudo de caso com docentes, tutores e discentes

"Apoio técnico administrativo para realização de videoconferências e videoaulas". Contudo, o telefone é um recurso ainda bastante utilizado no curso para a comunicação instantânea nos polos que têm maior dificuldade de acesso à internet.

Diante desta realidade, outra questão colocada aos alunos, docentes e tutores refere-se à utilização dos diferentes recursos tecnológicos para a realização das atividades acadêmicas. A maioria dos alunos considera: 'Muito alto' para os "AVA (Moodle)"; 'Alto' para os "Encontros presenciais"; 'Médio’ para "Dinâmica de grupo"; 'Baixo’ para "Videoaula" e 'Muito Baixo' para o "Podcast". A maioria dos docentes avaliou também: 'Muito Alto' para o item "AVA (Moodle)"; 'Alto’ para os itens "Material didático", "Encontros presenciais", "Tutoria" e "Perguntas Frequentes"; 'Médio' para "Videoaula"; 'Baixo' para "Podcast" e 'Muito Baixo'para o "Portfólio". Os tutores pesquisados, em sua maioria, mostra os níveis: 'Muito Alto' para o "AVA (Moodle)"; 'Alto' para "Encontros presenciais"; 'Médio' para "Videoaula"; 'Baixo' para "Dinâmica de grupo" e 'Muito Baixo’ para "Podcast".

Pelo exposto, o item "AVA (Moodle)" foi avaliado como de utilização "Muito Alto" pelos docentes, tutores e alunos ao mesmo tempo, visto que é este o ambiente virtual utilizado pelo curso de Biologia EaD adotado pela UFT. Foi também perguntado aos docentes, tutores e estudantes sobre os aspectos a serem melhorados na interação entre eles no curso de Biologia EaD estudado.

Apesar dos esforços institucionais, o acesso limitado à internet à diversas regiões do estado do Tocantins e a deficiência da infraestrutura e logística dos polos prejudicam a interação entre docentes, tutores e estudantes. Igualmente, os tutores T2, T3, T5 e T7 se referiram a mais encontros presenciais do curso com reuniões mais frequentes, aulas práticas e de campo de grupos de alunos, tutores e docentes do curso, reuniões, debates e semanas acadêmicas.

O que é corroborado pelos docentes D2, D4 e D5, que sugerem que mais encontros presenciais permitiriam maior interação nas aulas práticas de laboratório, estágio e TCC, como também com os grupos de pesquisa e extensão, além de reuniões regulares entre professores e tutores. Por outro lado, o docente D5 aponta a "Rotatividade de professores em aulas presenciais em cada polo", como um item a ser observado, uma vez que a interação entre docentes, tutores e estudantes passou a ser vista efetivamente como uma relação dialógica pela possibilidade de negociação, autoria, criatividade e autonomia entre os envolvidos. Também os alunos A1, A2, A3, A5, A12 e A19 manifestaram que se deve vivenciar a "prática", haver mais encontros presenciais semanalmente e maior número de 
aulas práticas e de campo, em laboratório, com visitas e estudos a projetos de conservação e proteção da flora, fauna e vida marinha.

Levando-se em conta que as tecnologias contribuem para os debates e diálogos, o aluno A17 observa que "o que deixa a desejar são as ferramentas que são poucas utilizadas", o tutor T9 acrescenta que há necessidade de "[...] melhor utilização dos instrumentos interativos da plataforma moodle; inserção dos 'processos interativos' no planejamento realizado pelos professores" e o docente D4 considera que deve melhorar o "Apoio técnico administrativo para realização de videoconferências e videoaulas", além de "o uso dos fóruns precisa ser melhor" (A6). Nesse sentido, o curso deve atentar para ampliar e melhorar as formas de comunicação, interatividade e de conversações, facilitando o diálogo entre a turma, docentes e tutores. Não se pode considerar somente as ferramentas, mas sim a interação, o que se passa entre os participantes.

\section{Considerações finais}

Seguindo uma abordagem sistêmico-relacional, este estudo mostra que é importante a forma como se dá a interação, a relação que se estabelece entre os participantes, que pode acontecer de forma simultânea, como a interação mútua e a interação reativa (PRIMO, 2003).

Os dados coletados no curso de Biologia EaD estudado revelaram que a interação ocorre de maneira mediana apresentando características reativas em aspectos como: interatividade entre docentes, tutores e discentes; feedback/resposta aos alunos com relação às dúvidas do conteúdo; interação síncrona com participação nos chats, videoconferências, etc; interação assíncrona com participação nos fóruns, e-mail, etc. Vale destacar que o e-mail foi avaliado pela maioria dos docentes, tutores e estudantes pesquisados como tecnologia que promove maior interação no curso de Biologia $\mathrm{EaD}$. O ambiente virtual de aprendizagem (moodle) é de grande utilidade no curso, visto que é o AVA adotado pela instituição.

Entende-se, porém, que no atual estágio do desenvolvimento tecnológico, a interação mútua pode se estabelecer em ambientes de cursos a distância mediados pelas tecnologias. Mas ainda se precisa de tempo e de esforços até que isso se torne realidade. Por enquanto, o que se estabelece na relação docente-tutor-estudante mediada pelas tecnologias do curso de Biologia EaD é uma interação do tipo reativa. Além do mais, há que se considerar que o domínio das ferramentas síncronas e assíncronas para acessar os materiais, a internet com velocidade e facilidade, equipamentos mais modernos, nem sempre é possível nos polos mais 
A interação como indicador de qualidade na avaliação da educação a distância: um estudo de caso com docentes, tutores e discentes

distantes, em função do acesso limitado à internet, a deficiência da infraestrutura e logística, prejudicando a interação entre os participantes.

Os dois tipos de interação aqui apresentados - mútua e reativa - podem valorizar a importância do contexto na interação no curso pesquisado. Porém, é importante ressaltar que, segundo Primo (2003), não são exclusivos, podendo acontecer várias interações de forma simultânea. Além disso, é necessário perceber que na relação entre elas, não existe necessariamente uma relação do tipo "ou é mútua ou é reativa", variando em intensidade. Em muitas circunstâncias, o interagente percorrerá por sistemas fechados e depois poderá entrar em sistemas abertos e virtuais. Por exemplo, um CD-ROM ou site que ofereça informações gravadas, de links fechados, pode permitir em uma janela abrir um chat onde as pessoas possam debater com outras que tenham acessado e visitado o site, ocorrendo, então, uma interação mútua.

Assim, o estudo demonstra a essencialidade da interação no curso de Biologia EaD. Todavia, para que aconteça a interação mútua no ambiente virtual moodle potencializada pelas ferramentas tecnológicas, exige-se o preparo, a dinamicidade e a interatividade no AVA entre os envolvidos na virtualidade no processo de ensinar e aprender. Pode-se perceber que o moodle pode proporcionar uma interação mútua por ser um sistema de grande utilidade para os docentes, tutores e estudantes. Porém, é necessário que as pessoas se engajem e vão construindo a relação de forma negociada e interdependente numa perspectiva relacional.

Diante das exposições dos alunos, acredita-se que o curso de Biologia EaD deve viabilizar uma aprendizagem preocupada com a realidade deles, com ferramentas tecnológicas e pedagógicas e interativas que estimulem a formação de cidadãos com autonomia e conscientes do desafio da aprendizagem e dos mecanismos de interação entre professores, tutores e estudantes.

Por outro lado, constata-se que o instrumento de avaliação do MEC não apresenta indicadores que explicitem se há excelência na interação como garantia de padrão de qualidade do curso em estudo, mas sim, se existem níveis de qualidade na avaliação do curso. Deve-se então discutir no âmbito do curso de que forma usar os mecanismos de interação do item 1.19 do Instrumento de Avaliação de Cursos de Graduação presencial e a distância (BRASIL, 2015b), visto que não explicita esses mecanismos, mas apenas recomenda que o PPC deva explicitá-los de modo a possibilitar ao estudante a aquisição de conhecimentos e habilidades, bem como desenvolver a sociabilidade, por meio de atividades de comunicação, interação e troca de experiências, não bastando garantir apenas a estrutura tecnológica. 
Entende-se que o processo de avaliação externa de cursos de graduação a distância pelo MEC deveria considerar como obrigatório entre seus indicadores de qualidade os mecanismos de interação e o mínimo de recursos tecnológicos digitais como forma de comunicação entre as pessoas, como fator de potencialização para as práticas pedagógicas e, consequentemente, para a produção do conhecimento. Deveria prever a organização do currículo em rede a ser composta por recursos apoiados em ambientes virtuais de aprendizagem, tecnologias analógicas e digitais, material didático online, sistemas de avaliação incorporando a ciberescrita, potencializando a comunicação síncrona e assíncrona, aprendizagem ubíqua em que o estudante pudesse estar conectado à rede em qualquer lugar e momento, etc., além do acompanhamento e avaliação da infraestrutura e logística que propiciem e articulem efetiva interação e complementariedade entre o presencial e o virtual. Além disso, há necessidade de se considerar a disponibilidade de formar equipe multidisciplinar e disponibilizar recursos financeiros para tal finalidade.

Faz-se necessário, portanto, que a avaliação dos mecanismos de interação entre os docentes, tutores e estudantes presente no Instrumento de Avaliação de Cursos de Graduação presencial e a distância (BRASIL, 2015b) de fato traduza as tecnologias digitais, as metodologias e os recursos educacionais, materializados em ambiente virtual multimídia interativo, materiais didáticos online, bem como os sistemas de acompanhamento e de avaliação de aprendizagem em rede.

Toda essa reflexão se faz premente uma vez que é na dinâmica de comunidades de aprendizagem potencializadas por recursos tecnológicos digitais que se dá o processo de interação entre educador e educando. É na apropriação dos recursos da internet aplicados ao ensino e a aprendizagem que o conhecimento se produz na educação superior, possibilitando ao mesmo tempo a construção, a modificação e a ressignificação dos sujeitos. Considera-se, todavia, a necessidade de se desenvolver mais pesquisas na área, visto que são ainda, incipientes, para que, a educação a distância, por meio da interação como característica fundamental nessa modalidade de ensino, se consolide, efetivamente, numa modalidade de acesso ao ensino superior com qualidade. 
A interação como indicador de qualidade na avaliação da educação a distância: um estudo de caso com docentes, tutores e discentes

\section{Referências}

ALMEIDA, Maria Elizabeth B. de. Educação a distância na internet: abordagens e contribuições dos ambientes digitais de aprendizagem. Educação e Pesquisa, São Paulo, v. 29, n. 2, p. 327-340, jul./dez. 2003.

BARDIN, Lawrence. Análise de conteúdo. Lisboa, Portugal: Edições 70, 1977. Disponível em <http://pt.slideshare.net/RonanTocafundo/bardin-laurence-anlise-de-contedo>. Acesso em: 22 abr. 2015.

BRASIL. Decreto. 5.622/2005. Regulamenta o art. 80 da Lei $n^{0} 9.394$, de 20 de dezembro de 1996, que estabelece as diretrizes e bases da educação nacional. Disponível em:

<http://www.planalto.gov.br/ccivil_03/_ato2004-2006/2005/decreto/d5622.htm>. Acesso em: 01 maio 2015.

BRASIL. Presidência da República. Lei No 10.861, de 14 de abril de 2004. Institui o Sistema Nacional de Avaliação da Educação Superior (SINAES). Diário Oficial [da] da República Federativa do Brasil. Brasília, DF, 15 abr. 2004, Seção 1, p. 3-4, 2004.

BRASIL. Ministério da Educação. Secretaria de Educação a Distância. Referenciais de Qualidade para Educação Superior a Distância. Brasília, 2007.

BRASIL. Ministério da Educação. Conselho Nacional de Educação. Texto orientador para a audiência pública sobre Educação a Distância. Brasília, 2014.

BRASIL. Ministério da Educação. Conselho Nacional de Educação. Resolução CNE/CP N 2, de $1^{\circ}$ de julho de 2015. Define as Diretrizes Curriculares Nacionais para a formação inicial em nível superior (cursos de licenciatura, cursos de formação pedagógica para graduados e cursos de segunda licenciatura) e para a formação continuada. Diário Oficial [da] da República Federativa do Brasil. Brasília, DF, 02 jul. 2015. Seção 1, p. 8-12, 2015a.

BRASIL. Ministério da Educação. Instituto Nacional de Estudos e Pesquisas Educacionais Anísio Teixeira - Inep. Instrumento de Avaliação de Cursos de Graduação presencial e a distância. Brasília, 2015b. Disponível em:

<http://download.inep.gov.br/educacao_superior/avaliacao_cursos_graduacao/instrumentos/2 015/instrumento_avaliacao_cursos_graduacao_presencial_distancia.pdf >. Acesso em: 27 abr. 2015 .

BRASIL. Ministério da Educação. Resolução CNE/CES de 11 de março de 2016. Estabelece Diretrizes e Normas Nacionais para a Oferta de Programas e Cursos de Educação Superior na Modalidade a Distância. Diário Oficial [da] da República Federativa do Brasil. Brasília, DF, 14 mar. 2016. Seção 1, p, 23-24, 2016.

CRESWELL, John W. Projeto de Pesquisa: método qualitativo, quantitativo e misto. Porto Alegre: Artmed, 2007.

DIAS SOBRINHO, José. Universidade: processos de socialização e processos pedagógicos. In DIAS SOBRINHO, J.; BALZAN, Newton Cesar. (Orgs). Avaliação Institucional: teoria e experiências. São Paulo: Cortez, 2005.

KOEHLER, Cristiane; CARVALHO, Marie Jane S. Interação mútua e docência mediadora: Subsídios para avaliar a aprendizagem na educação online. In: SÁNCHEZ, J. Nuevas Ideas en Informática Educativa. Santiago, Chile: TISE, 2012. v. 8, p. 279-380.

LÉVY, Pierre. Cibercultura. Trad. Carlos Irineu da Costa. São Paulo: Ed. 34, 1999. 
NOVA, Cristiane; ALVES, Lynn. Estação online: a "ciberescrita", as imagens e a EAD. In: SILVA, Marco. Educação online: teorias, práticas, legislação, formação corporativa. São Paulo: Edições Loyola, 2006. p. 107-136.

PRIMO, Alex. Interação mútua e reativa: uma proposta de estudo. Revista da Famecos, Porto Alegre, n. 12, p. 81-92, jun. 2000. Disponível em:

<http://www.ufrgs.br/limc/PDFs/intmutua_reativa.pdf>. Acesso em: 30 abr. de 2015.

PRIMO, Alex. Ferramentas de interação em ambientes educacionais mediados por computador. Educação, Porto Alegre, v. 25, n. 44, p. 127-149, 2001. Disponível em: <http://www.pesquisando.atraves-da.net/ferramentas_interacao.pdf >. Acesso em 22 abr. 2015.

PRIMO, Alex. Interação mediada por computador: a comunicação e a educação a distância segundo uma perspectiva sistêmico-relacional. 2003. 292 f. Tese (Doutorado em Informática em Educação) - Universidade Federal do Rio Grande do Sul. Disponível em: <http://www.lume.ufrgs.br/bitstream_id/7759/000449573.pdf>. Acesso em: 22 abr. 2015.

PRIMO, Alex. Interação mediada por computador: comunicação, cibercultura, cognição. 3. ed. Porto Alegre: Sulina, 2011.

SANTAELLA, Lúcia. Navegar no ciberespaço: o perfil cognitivo do leitor imersivo. São Paulo: Paulus, 2004.

SILVA, Marco. Criar e professorar um curso online: relato de experiência. In: SILVA, Marco (Org.). Educação online: teorias, práticas, legislação e formação corporativa. 2. ed. São Paulo: Edições Loyola, 2006. p. 53-75.

TRIVIÑOS, Augusto N. S. Introdução à Pesquisa em Ciências Sociais: A Pesquisa Qualitativa em Educação. Reimpressão. São Paulo: Atlas, 1987.

UNIVERSIDADE FEDERAL DO TOCANTINS. Relatório da Diretoria de Tecnologias Educacionais (DTE). Palmas. 2015.

WATZLAWICK, Paul; BEAVIN, Janet H.; JACKSON, Don D. Pragmática da Comunicação: um estudo dos padrões, patologias e paradoxos da interação. Tradução de Álvaro Cabral. São Paulo: Cultrix, 1967.

WILLIAMS, Raymond. Televison: Technology and cultural form. Londres: Routledge, 1979. YIN, Robert K. Estudo de caso: planejamento e métodos; trad. Daniel Grassi. 2. ed. Porto Alegre: Bookman, 2001. 
A interação como indicador de qualidade na avaliação da educação a distância: um estudo de caso com docentes, tutores e discentes

${ }^{1}$ Enedina Betânia Leite de Lucena Pires Nunes Universidade Federal do Tocantins | Reitoria | Campus Universitário de Palmas Palmas | TO | Brasil. Contato: enedina@uft.edu.br ORCID ${ }^{\text {ID }}$ https://orcid.org/0000-0002-0487-339X

${ }^{2}$ Isabel Cristina Auler Pereira Universidade Federal do Tocantins | Campus Universitário de Palmas | Programa de Pós-Graduação em Educação Palmas | TO | Brasil. Contato: isabel@uft.edu..br ORCID http://orcid.org/0000-0003-4740-5454

${ }^{3}$ Tânia Suely Azevedo Brasileiro Universidade Federal do Oeste do Pará | Instituto de Ciências da Educação | Programa de Ciências Exatas Santarém | PA | Brasil. Contato: brasileirotania@gmail.com ORCID https://orcid.org/0000-0002-8423-4466

Artigo recebido em 13 de outubro de 2016 e aprovado em 6 de junho de 2017. 